\title{
Modelos pronósticos en bacteriemia y sepsis
}

García Ordóñez MA, Colmenero Castillo JD. Modelos pronósticos en bacteriemia y sepsis. An Med Interna (Madrid) 2006; 23: 53-55.

Bacteriemia y sepsis son eventos íntimamente relacionados. El concepto de bacteriemia es esencialmente microbiológico, y se define como la presencia de bacterias en el torrente circulatorio (funguemia en caso de hongos) demostrada mediante hemocultivo. Mientras que sepsis es un concepto eminentemente clínico y consiste en el desarrollo de una respuesta sistémica a la infección.

En términos generales, la invasión del torrente sanguíneo supone un fracaso del sistema inmune por contener la infección en el foco primario. Si bien, también puede ser la expresión de la incapacidad del clínico en tratar correctamente la infección inicial. En último término la bacteriemia/fungemia supone la existencia de una infección diseminada que podría entrañar un peor pronóstico y dar lugar a focos secundarios de sepsis.

En su gran mayoría de las ocasiones la bacteriemia es transitoria o intermitente, salvo en las infecciones endovasculares como la endocarditis, en las cuales la bacteriemia suele ser continua. Por tanto la rentabilidad de un hemocultivo aumenta si la extracción del mismo se realiza coincidiendo con la bacteriemia transitoria que suele coincidir con el episodio de tiritona que precede al ascenso térmico (1).

Es importante recordar que la positividad de un hemocultivo no siempre es clinicamente relevante (2). Weinstein et al estudiaron 1.585 episodios de Bacteriemia/Fungemia en tres hospitales universitarios norteamericanos. De ellos 843 $(53,2 \%)$ fueron clínicamente relevantes y aún asumiendo los $84(5,3 \%)$ de significado clínico incierto también lo fueran, 658 hemocultivos positivos $(41,5 \%)$, se consideraron contaminaciones (3).

En las últimas décadas se ha observado un incremento en la incidencia de bacteriemias que ha venido parejo a los cambios producidos en la práctica médica, influenciada en parte por los avances tecnológicos y por otro por el envejecimiento de la población, con grupos de pacientes que reciben tratamientos agresivos e inmunosupresores. Es más, el aumento de incidencia observado se ha acompañado de cambios en el patrón de la bacteriemia, en cuanto a microorganismos aislados (mayor aislamiento de gérmenes gram positivos), fuente de infección, adquisición comunitaria o nosocomial, resistencia a los antimicrobianos, entre otros factores (4). A pesar de que la mortalidad por bacteriemia ha sufrido un descenso respecto a décadas previas gracias a la disponibilidad de nuevos y potentes antibióticos, esta sigue siendo alta (5). Existe un gran interés en identificar que factores influencian la evolución de los pacientes con bacteriemia, que puedan ayudar al clínico en la toma de decisiones sobre el manejo diagnóstico y terapéutico inicial. En este sentido, se han publicado múltiples trabajos en pacientes con bacteriemia tratando de identificar factores predictivos de evolución desfavorable (sepsis y mortalidad) (6).

En el presente número de ANALES DE MEDICINA INTERNA se publican varios trabajos relacionados con factores predictivos en bacteriemia y sepsis. Eroles Vega et al (7) en un estudio prospectivo de 204 pacientes ingresados en un servicio de Medicina Interna que presentaron temperatura igual o superior a $38{ }^{\circ} \mathrm{C}$ establecen factores que se asocian de forma independiente a infección, bacteriemia, sepsis y muerte. Por otro lado, García Ordóñez et al (8) en el análisis de 242 episodios de bacteriemia clínicamente relevante en pacientes ancianos ingresados tanto en áreas médicas como quirúrgicas identifican aquellos factores predictivos de adquisión nosocomial y su relación con el tipo de microorganismo. Por último, Sanz Carabaña et al (9) identifican factores pronósticos asociados a mortalidad en un grupo de 75 pacientes hospitalizados por bacteriemia comunitaria.

La aplicación de modelos de predicción clínica en bacteriemia y sepsis es, cuanto menos, difícil y probablemente solo se puedan usar en el ámbito donde han sido elaboradas (6). Esto es debido a que tanto la bacteriemia como la sepsis son entidades que engloban una gran cantidad de escenarios clínicos diferentes, dependiendo de la zona geográfica y hospital estudiado, gérmenes involucrados, fuentes de infección, adquisición comunitaria o intrahospitalaria, gravedad de las enfermedades subyacentes o debilitantes que presenten los pacientes, etc, siendo difícil extrapolar los modelos predictivos de un ámbito a otro. La sepsis es una respuesta sistémica fluctuante y dinámica desarrollada ante la infección y dependiente de factores individuales, genéticos y del entorno, con la dificultad de generar factores predictores universales que estimen la evolución del paciente (10). 
La incidencia de bacteriemia y sepsis es difícil de estimar dada la heterogeneidad en cuanto a definición de caso que se han utilizado (11). En 1991, a partir de la conferencia de consenso se ha homogenizado la definición de sepsis siguiendo los criterios de Bone y sus formas evolutivas más graves (sepsis grave y shock séptico), (12) Esta clasificación probablemente suponga una excesiva simplificación y no sea suficiente para caracterizar de forma precisa la gravedad de los enfermos con sepsis $(13,14)$. Levy et al han propuesto un nuevo sistema de estratificación basado en 4 aspectos: predisposición, infección, respuesta y disfunción de órganos (15). En las últimas dos décadas se ha observado un incremento de bacteriemias y sepsis, con incidencias de 5-28 episodios/1.000 pacientes y 175 casos/100.000 pacientes respectivamente (16-18).

La bacteriemia en general y la sepsis particular es un acontecimiento grave que depara una mortalidad atribuible entre $30-50 \%$. La tasa de mortalidad muestra una gran variabilidad en los diferentes estudios realizados, con una marcada heterogeneidad de los pacientes incluidos y diferente definición y gravedad de los casos de bacteriemia y sepsis, así como la distinta medida de los resultados (mortalidad cruda, atribuible, intrahospitalaria, a 30 días) (19,20).

Muchos autores han analizado factores pronósticos de mortalidad en cohortes de pacientes con bacteriemia y sepsis, siendo los más recurrentemente identificados la adecuación de tratamiento antibiótico, la presencia de enfermedad subyacente, la fuente y tipo de infección, la presencia de shock con necesidad de drogas vasoactivas, la disfunción múltiple de órganos y la neutropenia (21).

Los agentes microbiológicos causantes de bacteriemia y sepsis pueden no solo afectar la evolución sino también condicionar la toma de decisiones inicial del clínico. Hay una amplia variación en las tasas de mortalidad según el microorganismo causante. Así, la bacteriemia por enterobacterias (salvo E. coli) y funguemias tienen las tasas más altas de mortalidad (30-50\%), así como el aislamiento polimicrobiano (35\%). Mientras la bacteriemia por estafilococcus coagulasa negativo y E. coli presentan tasas de mortalidad más bajas (10-15\% y $13-17 \%$ respectivamente) $(3,11,21)$. Por otro lado la fuente de bacteriemia también condiciona una gran variabilidad en las tasas de mortalidad. La fuente de infección intraabdominal, del tracto respiratorio inferior o es desconocida se asocia a una mayor mortalidad $(11,22)$. Clásicamente se ha atribuido a la bacteriemia de adquisición nosocomial una mortalidad considerablemente superior a la de la bacteriemia de origen comunitario (3). En la actualidad, estas diferencias probablemente sean menos dramáticas. Sin embargo, dentro de las bacteriemias nosocomiales también existe una gran heterogeneidad como lo demuestran los recientes resultados del estudio SCOPE (Surveillance and Control of Pathogens of Epidemiological Importance Project), en el que se incluyen 24.179 episodios de bacteriemia recogidos en 49 hospitales. En este estudio se demuestra que la mitad de todos los episodios de bacteriemia nosocomial se presentan en las Unidades de Cuidados Intensivos, la mortalidad de los episodios debidos a $\mathrm{P}$ aeruginosa supera el $50 \%$ y la proporción de episodios causados por organismos resistentes aumenta de forma alarmante (23).

La presencia de enfermedades subyacentes debilitantes (neoplasia, cirrosis hepática, insuficiencia renal) también condiciona un peor pronóstico $(3,11,21)$. Diversos trabajos han mostrado la relación entre varios marcadores biológicos (proteína $\mathrm{C}$ reactiva, procalcitonina, interleucina 6 y factor de necrosis tumoral) y una evolución más desfavorable de la sepsis (13).

Por tanto, bacteriemia y sepsis conforman un conjunto heterogéneo de escenarios clínicos muy diversos entre si dependientes de aspectos tanto individuales de los propios pacientes como del entorno donde se produce la infección, lo que complica la aplicación y generalización de diferentes modelos de predicción clínica.

\section{A. GARCÍA ORDÓÑEZ, J. D. COLMENERO CASTILLO}

Servicio de Medicina Interna. Unidad de Enfermedades Infecciosas. Hospital Regional Universitario Carlos Haya. Málaga

\section{Bibliografía}

1. Bryan CS. Clinical implications of positive blood cultures. Clin Microbiol Rev 1989; 2: 329-53.

2. MacGregor RR, Beaty HN. Evaluation of positive blood cultures:guidelines for early differentiation of contaminated from valid positive cultures. Arch Intern Med 1972; 130: 84-7.

3. Weinstein MP, Towns ML, Quartey SM, Mirret S, Reimer LG, Parmigiani $\mathrm{G}$, et al. The clinical significance of positive blood cultures in the 1990s: a prospective comprehensive evaluation of the microbiology, epidemiology, and outcome of bacteraemia and fungemia in adults. Clin Infect Dis 1997; 24: 584-602.

4. Moss M, Martin GS. A global perspective on the epidemiology of sepsis. Intensive Care Med 2004; 30: 527-9.

5. Martin GS, Mannino DM, Eaton S, Moss M. The epidemiology of sepsis in the United States from 1979 through 2000. N Engl J Med 2003; 348: $1546-54$

6. Modol Deltell JM, Sabria M. Modelos de predicción de bacteriemia. Med Clin (Barc) 2004; 123: 255-6.

7. Eroles Vega G, Fernández Pérez C, del Valle Loarte P, Márquez Salas M, Mendivil Ferrer M, García Ibarz U, et al. Fiebre en

pacientes hospitalizados en un Servicio de Medicina Interna: análisis prospectivo de 204 casos. An Med Interna (Madrid) 2006; 23: 56-61.

8. García Ordóñez MA, Moya Benedicto R, López González JJ, Colmenero JD. Características epidemiológicas de la bacteriemia de origen comunitario y nosocomial en pacientes hospitalizados mayores de 65 años. An Med Interna (Madrid) 2006; 23: 62-65.

9. Sanz Carabaña P, Ramos Martínez A, Asensio Vegas A, García Navarro MJ, Linares Rufo M. Mortalidad y factores pronósticos en pacientes hospitalizados por bacteriemia adquirida en la comunidad. An Med Interna (Madrid) 2006; 23: 66-72.

10. Hotchkiss RS, Kart IE. The pathophysiology and treatment of sepsis. N Engl J Med 2003; 348: 138-50.

11. Angus DC, Wax RS. Epidemiology of sepsis: an update. Crit Care Med 2001; 29: S109-16.

12. Bone RC, Balk RA, Cerra FB, et al. Definitions for sepsis and organ failure and guidelines for the use of innovative therapies in sepsis: The ACCP/SCCM Consensus Conference Committee. Chest 1992; 101: 1644-55. 
13. Santolaria F. Indicadores de gravedad en la sepsis. Med Clin (Barc) 2003; 121: 378-80.

14. Vincent JL. Dear SIRS, I'm sorry to say that I don't like you. Crit Care Med 1997; 25: 372-4.

15. Levy MM, Fink MP, Marshall JC, Abraham E, Angus D, Cook D, et al. 2001 SCCM/ESICM/ACCP/ATS/SIS international sepsis definitions conference. Crit Care Med 2003; 31: 1250-6.

16. Ruiz-Giardin JM, Noguerado Asensio A. Bacteriemias. An Med Interna (Madrid) 2005; 22: 105-7.

17. Bouza E, Pérez-Molina J, Muñoz P. Report of ESGNI01 and ESGNI02 studies. Bloodstream infections in Europe. Clin Microbiol Infect 1999; 5: 2S1-12.

18. Center for Disease Control. Increase in national hospital discharge survey rates for septicaemia: United States, 1979-1987. MMWR 1990; 39: 31-4.
19. Friedman G, Silva E, Vincent JL. Has the mortality of septic shock changed with the time. Crit Care Med 1998; 26: 2078-86.

20. Cohen NH. Reduced mortality from septic shock: lessons for the future. Crit Care Med 1998; 26: 1956-8.

21. Herchline T, Gros S. Improving clinical outcome in bacteraemia. J Eval Clin Pract 1998; 4: 191-5.

22. Rello J, Ricart M, Mirelis B, et al. Nosocomial bacteriemia in a medical-surgical intensive care unit: epidemiologic characteristics and factors influencing mortality in 111 episodes. Intensive Care Med 1994; 20: 94-8.

23. Wisplingoff H. Bischoff T, Tallent SM, Seifert H, Wenzel RP, Edmond MD. Nosocomial bloodstream infections in US hospitals: analysis of 24,179 cases from a prospective nationwide surveillance study. Clin Infect Dis 2004; 39: 309-17. 